\title{
Clinical effects of lentinan combined with budesonide inhalation in treating acute exacerbation of chronic obstructive pulmonary disease under mechanical ventilation
}

\author{
JIAN SUN and GANG ZHAO \\ Department of Emergency, Shanghai Jiao Tong University Affiliated Sixth People's Hospital, Shanghai 200233, P.R. China
}

Received March 17, 2018; Accepted September 24, 2018

DOI: $10.3892 /$ etm.2019.7149

\begin{abstract}
In the present study, the clinical efficacy of the immune modulator lentinan combined with inhalation of the corticosteroid budesonide in treating acute exacerbation of chronic obstructive pulmonary disease (AECOPD) under mechanical ventilation was assessed. A total of 72 cases of AECOPD treated at Shanghai Jiao Tong University Affiliated Sixth People's Hospital (Shanghai, China) between June 2016 and September 2017 were enrolled. The AECOPD patients were randomly divided into an experimental group $(n=36)$ and a control group $(n=36)$. All of the patients received ventilator support and endotracheal intubation was performed. The experimental group was orally administered lentinan and budesonide was administered via atomization inhalation through a Y-tube and the control group received only budesonide via Y-tube. After the treatment, airway pressure, the time of mechanical ventilation and the time of stay at the intensive care unit for the experimental group were significantly lower than those for the control group $(\mathrm{P}<0.001)$. The plasma levels of adiponectin, D-dimer, interleukin-17 and high-sensitivity $\mathrm{C}$-reactive protein, as well as the pressure of $\mathrm{CO}_{2}$ in the experimental group were significantly lower than those in control group $(\mathrm{P}<0.001)$. Furthermore, the partial $\mathrm{O}_{2}$ pressure in the experimental group was significantly higher than that in the control group $(\mathrm{P}<0.001)$. After the combined treatment, the proportions of $\mathrm{CD}^{+}$and $\mathrm{CD} 4^{+} \mathrm{T}$-cells in the blood were elevated, while the proportion of $\mathrm{CD} 8^{+} \mathrm{T}$-cells was decreased, compared with those in the experimental group at baseline or the control group post-treatment. In conclusion, the strategy of lentinan treatment combined with budesonide inhalation for AECOPD patients under mechanical ventilation demonstrated
\end{abstract}

Correspondence to: Mr. Gang Zhao, Department of Emergency, Shanghai Jiao Tong University Affiliated Sixth People's Hospital, 600 Yishan Road, Shanghai 200233, P.R. China

E-mail: zhaogang64369181@sohu.com

Key words: acute exacerbation of chronic obstructive pulmonary disease, lentinan, budesonide, mechanical ventilation, inhalation improved clinical efficacy compared with budesonide alone. (Chinese Clinical Trial Registry no. ChiCTR1800019088).

\section{Introduction}

COPD is one of the leading causes of death worldwide. Of note, patients with AECOPD and ventilator support in the intensive care unit (ICU) have a higher risk of death and disability $(1,2)$. The duration of mechanical ventilation support has an impact on healthcare costs as well as quality of life (3), and directly affect the prognosis of patients with AECOPD $(4,5)$. It is important to terminate mechanical ventilation early to prevent infection, airway pressure injury and ventilator dependence (6). The standard of management for acute exacerbation inpatients with moderate-to-severe COPD includes supplemental oxygen, non-invasive or invasive mechanical ventilation, short-acting inhaled bronchodilators, systemic corticosteroids and antibiotics (7). Non-pharmacologic management includes ventilator support and administration of supplemental oxygen.

Lentinan is a well-recognized immunomodulator, which is extracted from shiitake (8). AECOPD medications include bronchodilator, anti-infective drugs as required and systemic cortical hormone, but systemic corticosteroid treatment has obvious adverse effects, including hyperglycemia, osteoporosis and vertebral compression fractures. Corticosteroid inhalation therapy is effective and due to its lower dosage, it causes less adverse reactions, and has almost no direct effects on target organs and the blood circulation (9). A previous study has indicated that short-term corticosteroid therapy was as effective as long-term therapy (10). Budesonide suspension (Pulmicort Respules) is currently used as inhaled corticosteroids. Another advantage of atomization inhalation therapy is that corticosteroid may be mixed with bronchodilator, including $\beta 2$ agonists and anti-cholinergic drugs, which rapidly relieve symptoms. In patients with severe COPD inhaled corticosteroids may reduce the number of exacerbations, the degree of acute exacerbations and the risk of mortality (10).

Studies reporting on the use of corticosteroids and lentinanin critically ill patients with AECOPD on ventilator support are scarce. The present study, the outcome of combined usage of inhaled immunomodulator and corticosteroid in patients with AECOPD was compared. In the present study, the clinical 
efficacy of lentinan combined with budesonide inhalation in AECOPD patients receiving ventilation support at the ICU was analyzed, and the serum concentrations of adiponectin (APN), D-dimer (D-D), interleukin (IL)-17 and high-sensitivity C-reactive protein (hs-CRP) were examined. Furthermore, the proportions of $\mathrm{CD}^{+}, \mathrm{CD}^{+}$and $\mathrm{CD} 8^{+} \mathrm{T}$-cells were assessed to evaluate the immunity function of the patients.

\section{Materials and methods}

Patients. Written informed consent was obtained from all participants and the present study was approved by the Ethical Committee of Shanghai Jiao Tong University Affiliated Sixth People's Hospital (Shanghai, China). The Chinese clinical trial registry number is ChiCTR1800019088. A total of 72 cases of severe AECOPD admitted to the ICU between June 2016 and September 2017 with the requirement of ventilator support were enrolled. All of the patients were divided into two groups by a randomized, double-blinded method, including 36 cases in each group (experimental group: 20 males and 16 females; age, $54.69 \pm 5.33$ years; and healthy control group: 19 males and 17 females; age, $58.54 \pm 8.01$ ). The retrospective patients were all without fatal outcome.

Inclusion and exclusion criteria. All of the patients were diagnosed according to the diagnostic criteria for AECOPD. The inclusion criteria were set in accordance with the Global initiative for chronic Obstructive Lung Disease (GOLD) spirometry definition (11). The exclusion criteria included the diagnosis of pneumonia or pulmonary embolism, asthma, heart failure, thromboembolic disease or restrictive respiratory insufficiency.

Therapies. The experimental group received oral administration of $0.5 \mathrm{~g}$ lentinan twice/day (Jinling Pharmaceutical Co., Ltd., Shenzhen, China) and inhalation of $2 \mathrm{ml}$ budesonide $(0.5 \mathrm{mg} / \mathrm{ml}$; Astra Zeneca Pharmaceutical Co., Ltd., Shanghai, China) twice a day (bid) over 4 days delivered by a breathing machine Y-tube. The control group only received budesonide atomization inhalation (bid over 4 days) via a breathing machine Y-tube. All patients received the same antibiotic therapy (cephalosporins).

Inclusion criteria included patients with a breathing rate $<30 /$ min, a normal cardiovascular function, no abnormal breathing and no airway irritability. The endotracheal intubation time was limited to $120 \mathrm{~h}$.

Clinicopathological characteristics, biochemistry and lung function. The full medical history was reviewed for each patient, and all subjects underwent a full clinical examination and pulmonary function tests. The airway pressure, mechanical ventilation running time, length of ICU stay and rate of trachea incision of patients were recorded. The plasma levels of APN, D-D, serum IL-17 and hs-CRP were measured for all of the patients prior to and after treatment (day 4). A total of $5 \mathrm{ml}$ fasting blood as obtained, and $2 \mathrm{ml}$ plasma was collected in Eppendorf tubes and centrifuged at 1,509 $\mathrm{x} \mathrm{g}$ for $10 \mathrm{~min}$ at $4^{\circ} \mathrm{C}$. The supernatant was put into a new Eppendorf tube and stored in an $-80^{\circ} \mathrm{C}$ refrigerator. APN (cat. no. 442308) and IL-17 (cat. no. 433918) quantitative ELISA kits were purchased from
BioLegend, Inc. (San Diego, CA, USA). The ELISAs for all standards and samples were performed in duplicate. The levels of APN and IL-17 were detected by reading the absorption at $450 \mathrm{~nm}$ using an ELISA plate reader (Bio-Rad Laboratories, Inc., Hercules, CA, USA) according to the protocol of the kits. The concentrations of the analyte proteins were determined through interpolation from a standard curve. ASYSMEX CA-7000 automatic blood coagulation analyzer was used to test the level of D-D through immune turbidimetry (reference value, $<0.3 \mathrm{mg} / \mathrm{l})$. A HITACHI 7600 automatic biochemical analyzer (Hitachi, Ltd., Tokyo, Japan) was used to determine the level of hs-CRP (reference value, 0-3 mg/l).

Flow cytometric analysis. The antibodies phycoerythrin-CD3 (cat. no. bs-10498R), fluorescein isothiocyanate-CD4 (cat. no. bs-0647R) and peridinin chlorophyll/cyanine 5.5-CD8 (cat. no. bs-0648R) were purchased from BIOSS (Beijing, China). Whole blood cells were obtained from patients. Cells were fixed with $70 \%$ methanol (overnight at $4^{\circ} \mathrm{C}$ ), permeabilized with $90 \%$ ice-cold methanol for $20 \mathrm{~min}$ at $-20^{\circ} \mathrm{C}$, counted and stained with the aforementioned antibodies at a dilution of $1: 1,000$ in $10^{6} / \mathrm{ml}$ cell suspension in dark for $30 \mathrm{~min}$ at $4^{\circ} \mathrm{C}$. Following washing, the populations of $\mathrm{CD}^{+}, \mathrm{CD}^{+}$and CD $8^{+}$T-cells were analyzed using a FACSCanto II (BD Biosciences, Franklin Lakes, NJ, USA).

Statistical analysis. Statistical analyses were performed using SPSS software (version 15.0; SPSS, Inc., Chicago, IL, USA). Measurement data were expressed as the mean \pm standard deviation. An unpaired t-test was used for comparison between two groups. One-way analysis of variance followed by Tukey's post hoc test was used for determining inter-group differences among multiple groups. Count data were presented as $\mathrm{n}(\%)$ and analyzed using the $\chi^{2}$ test. $\mathrm{P}<0.05$ was considered to indicate a statistically significant difference.

\section{Results}

Patient characteristics. A total of 80 consecutive patients with severe AECPOD were considered for enrollment. Among them, 3 cases were excluded due to inadequate medical record documentation and 5 patients died during the ICU stay. The baseline characteristics of evaluable cases included in the present analysis are listed in Table I. No differences in age, sex, disease severity, complications and pulmonary function between the experimental and the control group were noted prior to treatment $(\mathrm{P}>0.05)$.

Airway pressure of breathing machine, mechanical ventilation time and length of ICU stay. A comparison of airway pressure of the breathing machine, mechanical ventilation time and length of ICU stay between the experimental and the control group is provided in Fig. 1. The results indicated that the airway pressure of the breathing machine $(\mathrm{P}<0.001)$, the mechanical ventilation time $(\mathrm{P}<0.001)$ and the time of ICU stay $(\mathrm{P}<0.001)$ in the experimental group were significantly decreased compared with those in the control group.

Serum levels of $A P N, D-D, I L-17$ and $h s-C R P$. The laboratory analyses indicated that in each group, the plasma levels 

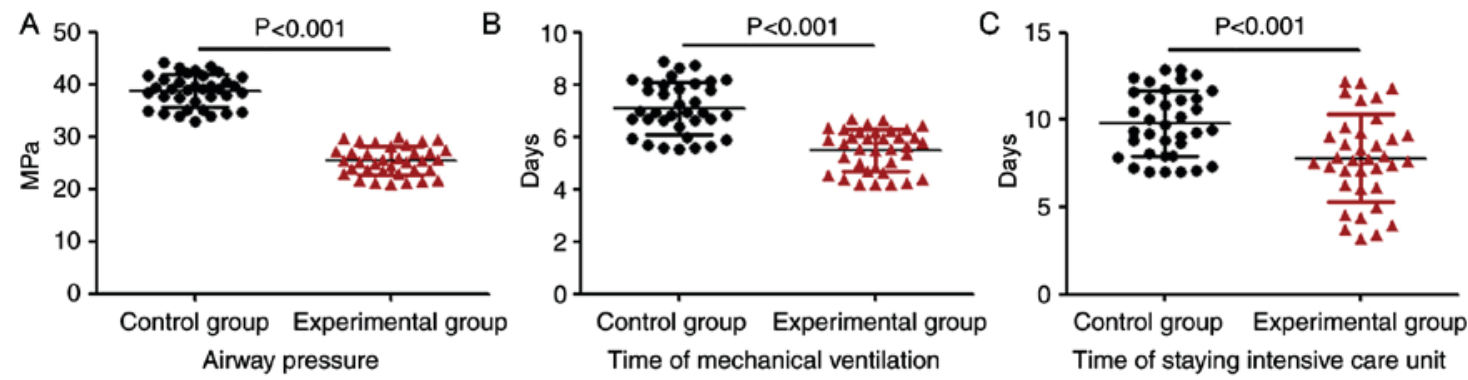

Figure 1. Comparison between patients with acute exacerbation of chronic obstructive pulmonary disease treated by administration of lentinan and budesonide, and those treated with budesonide only, under mechanical ventilation. The (A) airway pressure of the breathing machine, (B) mechanical ventilation time and (C) time of stay at the intensive care unit were compared between the two groups. Values are expressed as the mean \pm standard deviation.
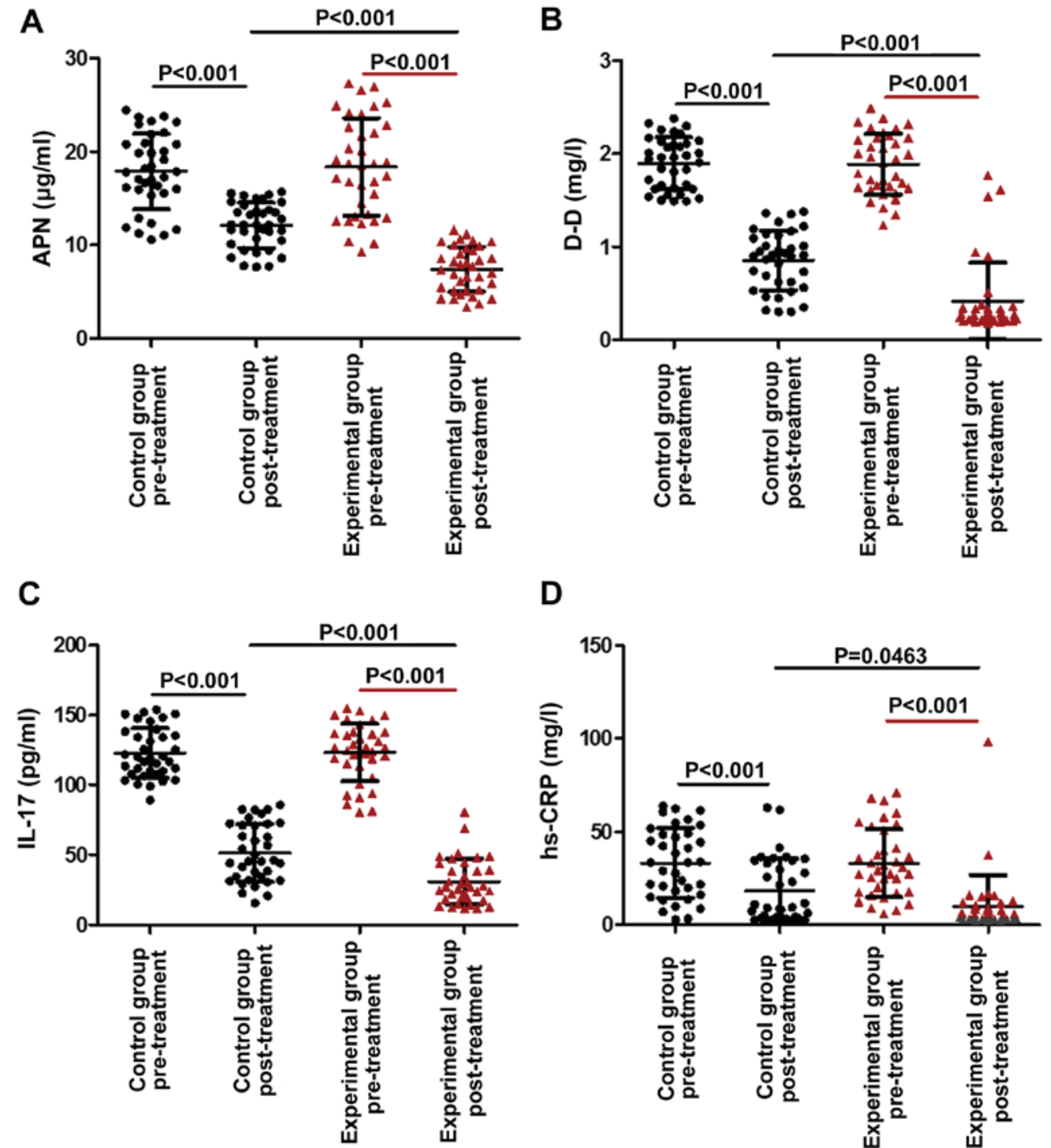

D

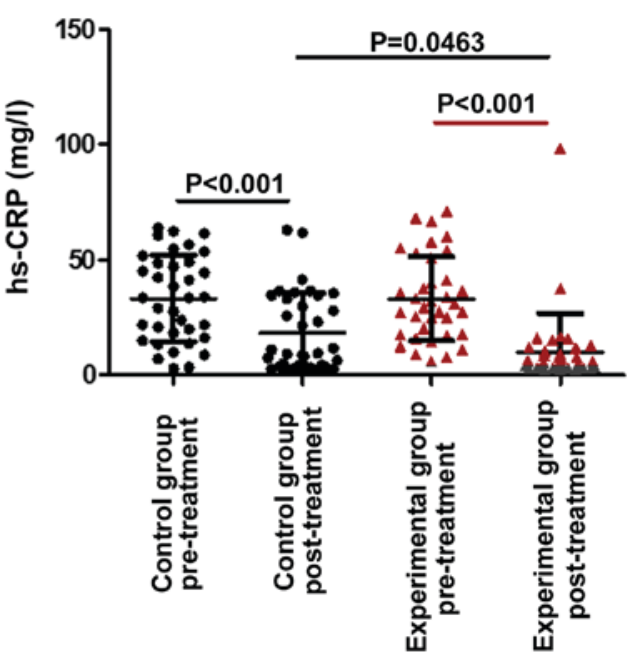

Figure 2. Comparison of the levels of APN, D-D, IL-17 and hs-CRP between AECOPD patients treated with lentinan and budesonide, and those who received budesonide only, under mechanical ventilation. (A) APN, (B) D-D, (C) IL-17 and (D) hs-CRP levels in the two groups prior to and post-treatment are provided. Values are expressed as the mean \pm standard deviation. AECOPD, acute exacerbation of chronic obstructive pulmonary disease. D-D, D-dimer; IL, interleukin; APN, adiponectin; hs-CRP, high-sensitivity C-reactive protein.

of APN, D-D, IL-17 and hs-CRP after treatment were obviously lower than those at baseline $(\mathrm{P}<0.05)$. Furthermore, the levels of APN $(\mathrm{P}<0.001), \mathrm{D}-\mathrm{D}(\mathrm{P}<0.001)$ and IL-17 $(\mathrm{P}<0.001)$ in the experimental group were significantly lower than those in the control group, suggesting that administration of lentinan in addition to budesonide in the experimental group further reduced the level of APN, D-D and IL-17 (Fig. 2A-C). Regarding the serum levels of hs-CRPs, the difference between the experimental and the control group after the treatment was not significant (Fig. 2D). After treatment, as 
Table I. Baseline characteristics of the patients.

\begin{tabular}{lcr}
\hline Parameter & Control $(\mathrm{n}=36)$ & Experimental group $(\mathrm{n}=36)$ \\
\hline Age (years) & $54.69 \pm 5.33$ & $58.54 \pm 8.01$ \\
Sex $($ male/female $)$ & $19(26.39 \%) / 17(23.61 \%)$ & $20(27.78 \%) / 16(22.22 \%)$ \\
BMI $\left(\mathrm{kg} / \mathrm{m}^{2}\right)$ & $30.12 \pm 6.87$ & $31.81 \pm 7.66$ \\
FEV $\%$ & $42.88 \pm 15.02$ & $41.57 \pm 16.45$ \\
FEV $/$ FVC & $40.87 \pm 17.98$ & $41.71 \pm 17.09$ \\
GOLD stage & & $12(16.67 \%)$ \\
1 & $16(22.22 \%)$ & $10(13.89 \%)$ \\
2 & $11(15.28 \%)$ & $7(9.72 \%)$ \\
3 & $6(8.33 \%)$ & $5(6.94 \%)$
\end{tabular}

Values are expressed as the mean \pm standard deviation or as $\mathrm{n}(\%)$. BMI, body mass index; $\mathrm{FEV}_{1}$, forced expiratory volume in one second; FVC, forced vital capacity; GOLD, Global initiative for chronic Obstructive Lung Disease.

Table II. Comparison of blood gas pressure parameters between the two groups.

\begin{tabular}{|c|c|c|c|c|}
\hline \multirow[b]{2}{*}{ Parameter } & \multicolumn{2}{|c|}{ Experimental group $(n=36)$} & \multicolumn{2}{|c|}{ Control $(n=36)$} \\
\hline & Pre-treatment & Post-treatment & Pre-treatment & Post-treatment \\
\hline $\mathrm{PaO}_{2}(\mathrm{mmHg})$ & $50.58 \pm 7.35$ & $78.82 \pm 8.57^{\mathrm{a}, \mathrm{b}}$ & $51.39 \pm 5.76$ & $67.39 \pm 11.25^{\mathrm{a}}$ \\
\hline $\mathrm{PCO}_{2}(\mathrm{mmHg})$ & $69.91 \pm 9.46$ & $46.71 \pm 9.28^{\mathrm{a}, \mathrm{c}}$ & $68.39 \pm 10.42$ & $53.15 \pm 9.72^{\mathrm{a}}$ \\
\hline
\end{tabular}

Values are expressed as the mean \pm standard deviation. ${ }^{\mathrm{a}} \mathrm{P}<0.001$ compared with pre-treatment; ${ }^{\mathrm{b}} \mathrm{P}<0.001$ compared with control group post-treatment; ${ }^{\mathrm{C}}<0.05$ compared with control group post-treatment. $\mathrm{PaO}_{2}$, partial oxygen pressure.

presented in Table II, the partial oxygen pressure $\left(\mathrm{PaO}_{2}\right)$ in two groups was significantly increased compared with the baseline value $(\mathrm{P}<0.001)$, while the $\mathrm{CO}_{2}$ pressure $\left(\mathrm{PCO}_{2}\right)$ was significantly decreased $(\mathrm{P}<0.001)$. Furthermore, the $\mathrm{PaO}_{2}$ in the experimental group was significantly higher than that in the control group $(\mathrm{P}<0.001)$, while the $\mathrm{PCO}_{2}$ was significantly lower $(\mathrm{P}<0.05)$.

Proportion of $\mathrm{CD}^{+}, \mathrm{CD}^{+}$and $C D 8^{+} T$-cells. The effect of lentinan combined with budesonide on the proportions of $\mathrm{CD}^{+}, \mathrm{CD}^{+}$and $\mathrm{CD}^{+}$T-cells was then examined. As presented in Fig. 3, the percentages of $\mathrm{CD}^{+}$and $\mathrm{CD}^{+} \mathrm{T}$-cells were significantly increased after treatment, compared with those at baseline and in the control group $(\mathrm{P}<0.01)$. In addition, the percentage of $\mathrm{CD}^{+} \mathrm{T}$-cells in the experimental group was decreased compared with that at baseline and in the control group $(\mathrm{P}<0.001)$.

\section{Discussion}

COPD has become an important public health problem due to the high mortality, as well as the social and economic burden associated with it. At present, COPD is the fourth most common cause of death worldwide. The World Bank and the World Health Organization have announced that COPD will be the world's fifth economic burden in 2020 (12). AECOPD in combination with respiratory failure is the most important reason for readmission of COPD patients to the hospital. Thus, it is of great significance to improve the means of prevention of AECOPD, and in particular, to improve the success rate of treating AECOPD combined with respiratory failure. Significant progress has been made regarding the clinical application of mechanical ventilation in the treatment of AECOPD, which has greatly improved the quality of life of affected patients (13).

COPD is a type of chronic bronchitis with characteristics of airflow obstruction and/or emphysema and progressive development, which is associated with airway hyper-responsiveness. The long-term use of a breathing machine leads to an increased incidence of ventilator-associated pneumonia (VAP) (14). For AECOPD patients with a VAP resistance phenomenon, generic drug-resistant boydii Acinetobacter strains, fungal infection and drug resistance have been observed (15), and adverse effects including an increase of airway damage were also observed (16). However, atomization therapy with budesonide may reduce airway resistance, breathing machine plenum pressure drop and airway pressure damage (17). The effect of standard doses of lentinan combined with budesonide for AECOPD has been rarely reported.

APN, secreted by fat cells, is an endogenous anti-inflammatory factor in airway epithelial cells, is released by autocrine and paracrine systems, and is a novel marker of airway 
A
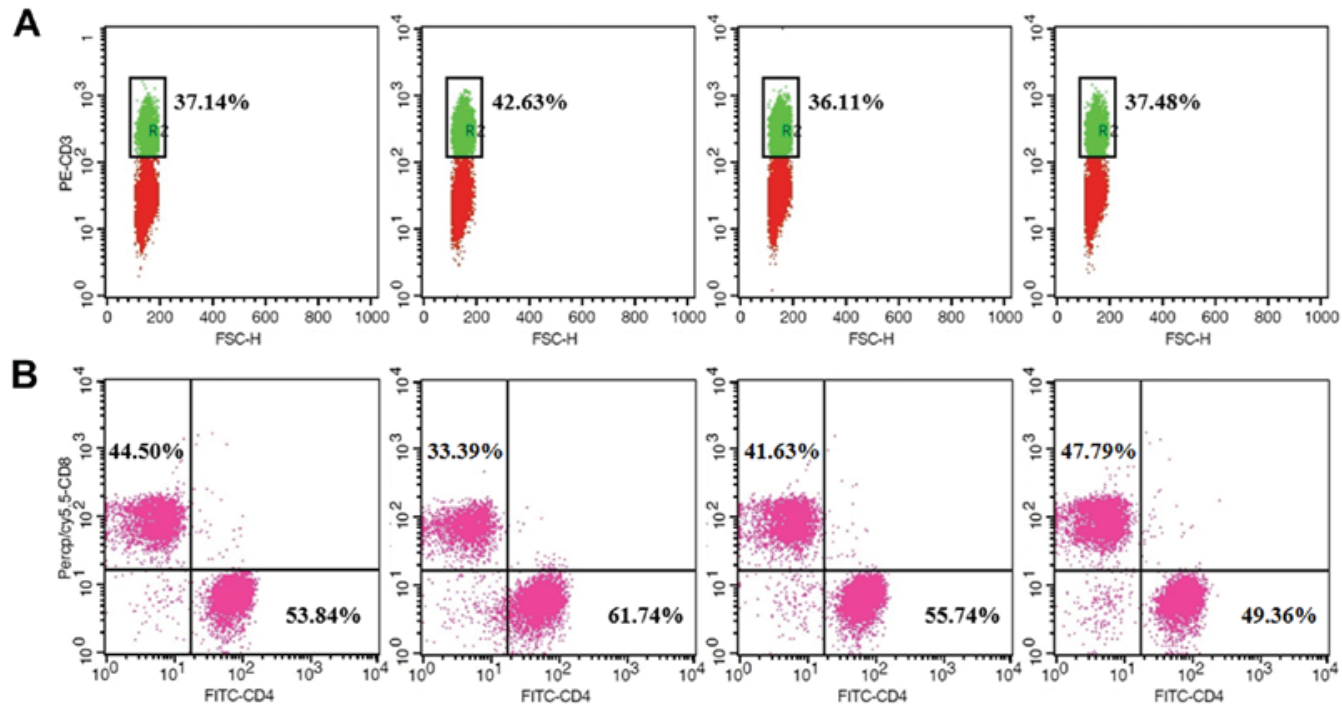

C
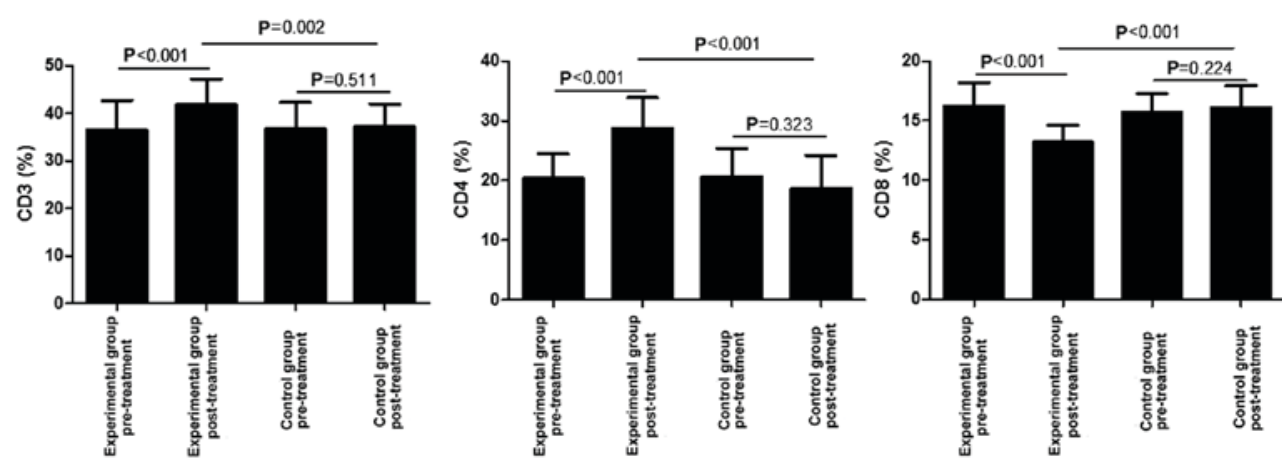

Figure 3. Analysis of $\mathrm{CD}^{+}, \mathrm{CD}^{+}$and $\mathrm{CD}^{+} \mathrm{T}$ cells in the blood of acute exacerbation of chronic obstructive pulmonary disease patients treated with lentinan and budesonide, and those who received budesonide only, under mechanical ventilation. (A) FACS plots of CD3 ${ }^{+} \mathrm{T}$ cells; $(\mathrm{B}) \mathrm{FACS}$ plots of $\mathrm{CD} 4^{+}$and $\mathrm{CD} 8^{+}$ T cells; (C) Average percentages of $\mathrm{CD}^{+}, \mathrm{CD}^{+}$and $\mathrm{CD}^{+} \mathrm{T}$ cells, calculated from the FACS analysis, prior to and post-treatment are provided. Values are expressed as the mean \pm standard deviation. FACS, fluorescence-assisted cell sorting; FITC, fluorescein isothiocyanate; Percp, peridinin chlorophyll; cy, cyanine; FSC, forward scatter; PE, phycoerythrin.

inflammation with a high predictive value for AECOPD. It was reported that the severity of COPD and the expression levels of APN were positively correlated $(18,19)$. COPD patients with chronic hypoxia, infection and accumulated inflammatory cytokines may develop endothelial damage, which eventually promotes thrombosis (20). D-D reflects the high coagulation state in the body and secondary fibrinolytic hyperfunction. IL-17 promotes the release of other associated inflammatory cytokines, causing neutrophil aggregation in the lung and damage to the structure of the airways (21). AECOPD is mostly caused by infection, with bacterial infection accounting for 40-50\% of AECOPD incidence (22). To the best of our knowledge, hs-CRP is a sensitive indicator that reflects bacterial infections.

The present study indicated that the airway pressure, usage time of breathing machine, length of stay at the ICU in the experimental group was significantly lower than that in the control group. The levels of APN, D-D, IL-17 and hs-CRP of AECOPD patients at baseline were higher than those after treatment, indicating the presence of a certain extent of infection, a high coagulation state and fibrinolytic hyperfunction in AECOPD patients. The levels of APN, D-D, IL-17 and hs-CRP after treatment were significantly lower than those prior to treatment in each group, suggesting that the infection, high coagulation state and fibrinolytic state were relieved. The levels of APN, D-D, IL-17 and hs-CRP in the experimental group were significantly lower than those in the control group, suggesting that the combined use of lentinan with budesonide is better than monotreatment with budesonide, which may therefore be worthy of implementation in the clinic. In comparison with those in the control group, the $\mathrm{PaO}_{2}$ was significantly increased and the $\mathrm{PCO}_{2}$ was significantly increased, suggesting that combination treatment of lentinan with budesonide provided a better outcome. Flow cytometric analysis suggested that combination of lentinan with budesonide greatly improved the immunity function of patients with AECOPD, which may contribute to the improved clinical outcome.

In the present study, only single dose of lentinan was administered to the experimental group, which indicated that lentinan could improve the immunity function and clinical outcome of patients with AECOPD. However, the optimal dose of lentinan were not determined in the current study. This represents a limitation and more studies are required to explore the clinical outcome of multiple dosages of lentinan and to analyze the optimal dose in AECOPD patients.

In summary, a significant benefit for AECOPD patients receiving mechanical ventilation was observed by combination treatment with lentinan and budesonide, with a shorter 
duration of mechanical ventilation, improvement of the serum levels of APN, D-D, IL-17 and hs-CRP, as well as the $\mathrm{PaO}_{2}$ and $\mathrm{PCO}_{2}$, as compared with the outcomes of treatment with budesonide alone. The present study provided a novel strategy for the combined administration of these medications.

\section{Acknowledgements}

Not applicable.

\section{Funding}

No funding was received.

\section{Availability of data and materials}

The datasets used and/or analyzed during the current study are available from the corresponding author on reasonable request.

\section{Authors' contributions}

GZ conceived and designed the study, wrote the manuscript and was involved in its critical revision. GZ and JS retrieved the samples and performed the experiments, they collected, processed and analysed the data and interpreted the results.

\section{Ethical approval and consent to participate}

Written informed consent was obtained from all participants and the present study was approved by the Ethical Committee of Shanghai Jiao Tong University Affiliated Sixth People's Hospital (Shanghai, China).

\section{Patient consent for publication}

Not applicable.

\section{Competing interests}

The authors declare that they have no competing interests regarding this study.

\section{References}

1. Spyratos D and Sichletidis L: Umeclidinium bromide/vilanterol combination in the treatment of chronic obstructive pulmonary disease: A review. Ther Clin Risk Manag 11: 481-487, 2015.

2. Zhong $\mathrm{J}$ and Roth $\mathrm{M}$ : Clinical potential of aclidinium bromide in chronic obstructive pulmonary disease. Ther Clin Risk Manag 10: 449-453, 2014.

3. Vitacca M, Bianchi L, Bazza A and Clini EM: Advanced COPD patients under home mechanical ventilation and/or long term oxygen therapy: Italian healthcare costs. Monaldi Arch Chest Dis 75: 207-214, 2011.

4. Faenza S and Petrini F: Mechanical ventilation in the emergency room. Minerva Anestesiol 66: 883-887, 2000 (In Italian).

5. Brijker F, van den Elshout FJ, de Rijk A, Folgering HT and Bosch FH: Use of noninvasive mechanical ventilation to avoid intubation during acute respiratory insufficiency. Ned Tijdschr Geneeskd 143: 1819-1823, 1999 (In Dutch).

6. Hashemian SM, Mortaz E, Jamaati H, Bagheri L, Mohajerani SA, Garssen J, Movassaghi M, Barnes PJ, Hill NS and Adcock IM: Budesonide facilitates weaning from mechanical ventilation in difficult-to-wean very severe COPD patients: Association with inflammatory mediators and cells. J Crit Care 44: 161-167, 2018.
7. Dixit D, Bridgeman MB, Andrews LB, Narayanan N, Radbel J, Parikh A and Sunderram J: Acute exacerbations of chronic obstructive pulmonary disease: Diagnosis, management, and prevention in critically ill patients. Pharmacotherapy 35: 631-648, 2015.

8. Liu YH, Ma SD, Fu QJ, Zhao LY, Li Y, Wang HQ and Li MC: Effect of lentinan on membrane-bound protein expression in splenic lymphocytes under chronic low-dose radiation. Int Immunopharmacol 22: 505-514, 2014.

9. Maltais F, Ostinelli J, Bourbeau J, Tonnel AB, Jacquemet N, Haddon J, Rouleau M, Boukhana M, Martinot JB and Duroux P: Comparison of nebulized budesonide and oral prednisolone with placebo in the treatment of acute exacerbations of chronic obstructive pulmonary disease: A randomized controlled trial. Am J Respir Crit Care Med 165: 698-703, 2002.

10. Ma Z and Zhang W: Short-term versus longer duration of glucocorticoid therapy for exacerbations of chronic obstructive pulmonary disease. Pulm Pharmacol Ther 40: 84-90, 2016.

11. Vogelmeier CF, Criner GJ, Martínez FJ, Anzueto A, Barnes PJ, Bourbeau J, Celli BR, Chen R, Decramer M, Fabbri LM, et al: Global strategy for the diagnosis, management, and prevention of chronic obstructive lung disease 2017 report: GOLD executive summary. Arch Bronconeumol 53: 128-149, 2017 (In English, Spanish).

12. Rudan I, Campbell H, Marušić A, Sridhar D, Nair H, Adeloye D, Theodoratou E and Chan KY: Assembling GHERG: Could 'academic crowd-sourcing' address gaps in global health estimates? J Glob Health 5: 010101, 2015.

13. Uren NG, Davies SW, Jordan SL and Lipkin DP: Inhaled bronchodilators increase maximum oxygen consumption in chronic left ventricular failure. Eur Heart J 14: 744-750, 1993.

14. Yalçınsoy M, Salturk C, Takır HB, Kutlu SB, Oguz A, Aksoy E, Balcı M, Kargın F, Mocin OY, Adiguzel N, et al: Case fatality rate related to nosocomial and ventilator-associated pneumonia in an ICU: A single-centre retrospective cohort study. Wien Klin Wochenschr 128: 95-101, 2016.

15. Boixeda R, Bacca S, Elias L, Capdevila JA, Vilà X, Mauri M and Almirall J: Pneumonia as comorbidity in chronic obstructive pulmonary disease (COPD). Differences between acute exacerbation of COPD and pneumonia in patients with COPD. Arch Bronconeumol 50: 514-520, 2014 (In English, Spanish).

16. McCurdy BR. Noninvasive positive pressure ventilation for acute respiratory failure patients with chronic obstructive pulmonary disease (COPD): An evidence-based analysis. Ont Health Technol Assess Ser 12: 1-102, 2012.

17. Xiong G, Xu L, Wei L and Li X: Atomization inhalation of terbutaline and budesonide efficiently improved immunity and lung function of AECOPD patients. Cell Mol Immunol 5: 287-291, 2008.

18. Leivo-Korpela S, Lehtimäki L, Vuolteenaho K, Nieminen R, Kööbi L, Järvenpää R, Kankaanranta H, Saarelainen $S$ and Moilanen E: Adiponectin is associated with dynamic hyperinflation and a favourable response to inhaled glucocorticoids in patients with COPD. Respir Med 108: 122-128, 2014.

19. Kirdar S, Serter M, Ceylan E, Sener AG, Kavak T and Karadağ F: Adiponectin as a biomarker of systemic inflammatory response in smoker patients with stable and exacerbation phases of chronic obstructive pulmonary disease. Scand J Clin Lab Invest 69: 219-224, 2009.

20. Zhang M, Zhang J, Zhang Q, Yang X, Shan H, Ming Z, Chen H, Liu Y, Yin J and Li Y: D-dimer as a potential biomarker for the progression of COPD. Clin Chim Acta 455: 55-59, 2016.

21. Beringer A, Noack M and Miossec P: IL-17 in Chronic Inflammation: From Discovery to Targeting. Trends Mol Med 22: 230-241, 2016.

22. Cai BQ, Cai SX, Chen RC et al. Expert consensus on acute exacerbation of chronic obstructive pulmonary disease in the People's Republic of China. Int J Chron Obstruct Pulmon Dis. 9:381-95, 2014.

This work is licensed under a Creative Commons Attribution-NonCommercial-NoDerivatives 4.0 International (CC BY-NC-ND 4.0) License. 